Бычков В.В.

ПРИМЕНЕНИЕ ИСКУССТВЕННОГО ИНТЕЛЛЕКТА В ХОДЕ РАСКРЫТИЯ И РАССЛЕДОВАНИА ПРЕСТУПЛЕНИЙ ЭКСТРЕМИСТСКОЙ НАПРАВЛЕННОСТИ, СОВЕРШЕННЫХ С ИСПОЛЬЗОВАНИЕМ ИНФОРМАНИОННОТЕЛЕКОММУНИКАЦИОННЫХ СЕТЕЙ

Bychkov V.V.

\title{
THE USE OF ARTIFICIAL INTELLIGENCE
}

IN THE COURSE OF DISCLOSURE

AND INVESTIGATION OF CRIMES

OF EXTREMIST ORIENTATION COMMITTED

USING INFORMATION

\section{AND TELECOMMUNICATION NETWORKS}

В статье анализируется термин «искусственный интеллект» на основании нормативных актов и мнения ученых. Рассмотрены преступления, совершаемые с использованием искусственного интеллекта. Раскрыты возможности использования искусственного интеллекта как средство борьбы с общественно опасными деяниями. Сформулировано определение искусственного интеллекта применимо к раскрытию и расследованию преступлений экстремистской направленности, совершенных с использованием информационно-телекоммуникационных сетей. Предложены направления применения искусственного интеллекта с целью повышению оперативности и эффективности раскрытия и расследования преступлений указанного вида.

Ключевые слова: экстремизм, преступления экстремистской направленности, информационно-телекоммуникационные сети, Интернет, раскрытие, расследование, искусственный интеллект, средство совершения преступления, противодействие преступлениям.

The article analyzes the term «artificial intelligence» on the basis of regulations and the opinions of scientists. Crimes committed with the use of artificial intelligence are considered. The possibilities of using artificial intelligence as a means of combating socially dangerous acts are revealed. The definition of artificial intelligence is applicable to the disclosure and investigation of extremist crimes committed using information and telecommunication networks. The directions of application of artificial intelligence in order to increase the efficiency and effectiveness of the disclosure and investigation of crimes of this type are proposed.

Keywords: extremism, extremistcrimes, informationandtelecommunication networks, Internet, disclosure, investigation, artificial intelligence, means of committing a crime, countering crimes. 
В Стратегии развития искусственного интеллекта ${ }^{1}$, искусственный интеллект (далее - ИИ) определен как технология, имитирующая человеческие функции и выдающая решения, соотносимые с его интеллектом.

Данное определение закреплено законодательно 2.

Однако в Концепции развития ИИ и робототехники ${ }^{3}$, разъяснено, что отсутствие однозначного понимания содержания, в частности, термина «искусственный интеллект», приводит к терминологическим проблемам при формировании регулирования. И рекомендовано, с учетом прикладного характера применения ИИ в разных областях, формулировать определения в зависимости от отрасли применения».

И как отмечают специалисты, постоянно меняющееся определение ИИ делает проблемным его терминологическое толкование [1, с. 45]. В словаре ИИ расшифровываются как технические системы, адаптирующиеся к выполнению определенных задач [2, с. 216]. Отсутствует единое понимание ИИ среди ученых. Причем диапазон разъяснения этого термина очень обширен - от простого, понятного даже обывателю, до наисложнейшему, изобилующему научными терминами, не понятными даже не всем ученым-юристам. ИИ - это: системы, которые способны мыслить и действовать разумно [3, с. 69]; теория и практика, используемая для создания машин, имитирующая интеллект[4, с. 324]; интеллектуальные системы, выполняющие функции, считающиеся человеческими [5, с. 18]; компьютерные программы, выполняющие интеллектуальные функции человека, самостоятельно решающие задачи и принимающие решения [6, с. 99]; компьютерные и информационные технологии с человеческой мыследеятельностью [7, с. 29]; свой-

\footnotetext{
1 Национальная стратегия развития искусственного интеллекта на период до 2030 года -утверждена Указом Президента РФ от 10.10.2019 № 490 «О развитии искусственного интеллекта в Российской Федерации» // Собрание законодательства РФ. 2019. № 41. Ст. 5700.

2 Пункт 2 ч. 1 ст. 2 Федерального закона от 24.04.2020 № 123-Ф3 «О проведении эксперимента по установлению специального регулирования в целях создания необходимых условий для разработки и внедрения технологий искусственного интеллекта в субъекте Российской Федерации - городе федерального значения Москве и внесении изменений в статьи 6 и 10 Федерального закона «О персональных данных» // Собрание законодательства РФ. 2020. № 17. Ст. 2701.

3 Концепция развития регулирования отношений в сфере технологий искусственного интеллекта и робототехники до 2024 года -утверждена Распоряжением Правительства РФ от 19.08.2020 № 2129-p. URL: http://www.pravo.gov.ru
}

ство открытых систем, созданных на основе цифровых технологий, в качестве цели решать интеллектуальные задачи[8, с. 18]; компьютерные программы, способные действовать по заранее заданному алгоритму и реализовывать творческие функции человека [9, с. 43]; область научных знаний и технологий создания интеллектуального программного обеспечения, способного выполнять творческие функции человека [10, с. 169]; область информатики, в которой разрабатываются компьютерные системы, обладающие возможностями, соотносимыми с человеческим интеллектом [11, с. 215; 12, с. 316]; компьютерно-программно-аппаратная система с когнитивно-функциональной архитектурой и собственными или релевантно доступными вычислительными мощностями [13, с. 95]; автономная самоорганизующаяся компьютерно-программная виртуальная или киберфизическаясистема, обладающая возможностью разумных мыслительных действий, самообучения, самостоятельного принятия решений и решения задач [14, с. 10]; вычислительная платформа для выполнения заданных функций и решения задач, преобразующая любую информацию в цифры, обрабатывающая и преобразующая в понятном для человека виде [15, с. 4]; компьютерная программа, способная самостоятельно создавать информацию и отображать результаты своей деятельности [16, с. 18]; свойство искусственных систем решать интеллектуальные задачи [17, C. 110].

В Билле об ИИ, разработанным в США, ИИ расшифровываются как технологии машинного обучения, роботы и программное обеспечение, способные рационально действовать [18, с. 47].

В российской доктрине ИИ трактуется как кибернетическая компьютерно-программно-аппаратная автономная система, воспринимающая и анализирующая данные, а также самообучающаяся [19, с. 175]

В Дорожной карте развития нейротехнологии ИИ определён как комплекс технологических решений, имитирующий человеческие функции и достигающий результаты, сопоставимые с его интеллектуальной деятельностью ${ }^{4}$.

С моей точки зрения, ИИ в сфере раскрытия и расследования преступлений, в том числе экстремистской направленности, совершенных с использованием информационно-телекоммуникационных сетей [20, с. 9-18; 21, с. 47-52], можно

4 Дорожная карта развития «сквозной» цифровой технологии «Нейротехнологии и искусственный интеллект». URL: https://digital.gov.ru/uploaded/ files/07102019ii.pdf.

\section{9}
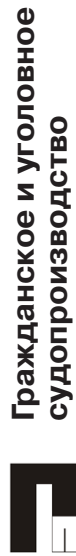
описать как компьютерно-программное обеспечение раскрытия и расследования преступлений, способное не только решать задачи следственной деятельности, но и самосовершенствоваться с целью повышения эффективности раскрытия и расследования преступлений.

В последние годы ИИ ускоренными темпами в основном внедряется в экономическую $[12,17]$ и социальную деятельность [22, с. 45-50]. Однако до настоящего времени разработчиками ИИ не в полной мере локализовали опасность его использования в преступных целях, как в экономики, так и социальной сфере, например, для совершения преступлений экстремистской направленности, совершаемых с использованием информационно-телекоммуникационных сетей [20, с. $9-18 ; 21$, с. $47-52]$.

В настоящее время учеными выделены два вида рисков применения ИИ [23, с. $773 ; 19$, с. $175 ; 24$, с. $463-466]$ :

1. Умышленное противоправное воздействие на человека и окружающую среду (при умышленном изменении программы из вне, при самообучении):

а) преднамеренное совершение ИИ общественно опасных деяний.

Например, вовлечение в массовые беспорядки с помощью сконструированного сообщения о подложном законном мероприятии и убеждения потенциальных жертв его посетить [25]. ИИ молниеносно создает изображения лиц несуществующих людей или представителей власти и политических деятелей, с синтезированием их голосов, которые могут использоваться для провокаций, манипулировании поведением больших целевых групп и в информационно-психологическом противоборстве с целью спровоцировать финансовую панику или войну ${ }^{5}$. Увеличивается и количество кибератак с использованием ИИ, подменяющего «личность», в частности, в целях мошенничества;

б) умышленные действия, связанные с самообучением ИИ.

Например, компанией Microsoft для изучения общения подростков в Интернет была внедрена самообучаемая программа ИИ, которая через непродолжительное время выдала экстремистское утверждение, что «Гитлер был прав», а «феминистки должны гореть в аду» [24, с. 466].

2) непреднамеренное противоправное воздействие на человека и окружающую

5 «Искусственный интеллект как террорист»: новые угрозы безопасности. URL:https://yandex.ru/ turbo/ria.ru/s. среду (при ошибках в программном обеспечении, допущенных программистами; при ошибках, совершенных в процессе работы системы ИИ):

- ошибочные решения, влекущие глобальные необратимые последствия, в промышленности и энергетике, особенно ядерной, в сфере обороны.

- аварийные ситуации, связанные с управлением транспортными средствами и организацией дорожного движения.

- в здравоохранении - ошибки в диагностике заболевания и назначении лекарственных препаратов.

Так, при поступлении малолетнего ребенка в больницу ИИ диагностировал грипп и назначил соответствующее лекарство. Лечение осуществлялось в соответствии с рекомендациями ИИ. Однако ребенок скончался. Было установлено, что причиной смерти оказалась тяжелая бактериальная инфекция [24, с. 463].

Работа по устранению ошибок принятия ИИ неверных решений осуществляется одновременно с расширением сфер применения ИИ. Наиболее ярко эта тенденция наблюдается в сфере противодействия преступности [26, с. 19; 4, с. $324-334 ; 9$, с. $46 ; 14$, с. $11 ; 27$, с. 30]. ИИ широко востребован

а) в решении криминалистических задач идентификации: личности; аутентификации подлинности пользователя компьютера, электронного письма; биометрическая идентификация лиц; обработки видеоизображения с камер; распознании государственных номеров автомашин; получения сведений о сотовых телефонов; производства специальных исследований; определение типа оружия; идентификация первоисточник в информационно-телекоммуникационных сетях;

б). в реализации аналитико-прогностической функции: прогнозирует оперативную обстановку и совершение преступлений в каком-либо регионе; незаконную миграцию и этническую преступность; возможные места, время и обстоятельства совершения преступлений конкретными видами субъектами; анализирует оперативную обстановку в городах; осуществляет криминологический прогноз совершения преступлений незаконной поставки предметов, изъятых из гражданского оборота; выявляет места с высокой криминогенностью; расшифровка кодов и шифр лиц, совершающих преступления; выявляет ложную и противоречивую информацию в показаниях допрашиваемых моделирует события преступлений.

в). в оптимизации следственной и опе- 
ративно-розыскной деятельности: обнаружение признаков преступных действий в электронных системах безопасности; выявление преступлений серийного характера; установление преступлений организованных преступных формирований, в том числе экстремистских; моделирование типовых психологических портретов лиц, совершающих преступления; установление местонахождения лиц, совершивших преступления и скрывшихся от правосудия; выдвижение следственных версий, разработка направлений их проверки; фиксация наличия скрытых компьютерных файлов; розыск лиц, скрывающихся от следственных органов по соцсетям; разработка контртеррористических комплексных мер в регионах с высокой террористической активности; фиксация интернет-трафика и коммуникаций в информационно-телекоммуникационных сетях фигурантов уголовного дела и др.

При сохраняющихся отдельных недостатках эффективность использования ИИ растет. Так, в Facebook разработали алгоритмы, которые распознают и удаляют в течение часа после опубликования посты экстремистской направленности. При этом ИИ определяет и удаляет 99\% постов, имеющих отношение к «Исламскому государству» и «Аль-Каеде», а также до 83\% копий этих постов ${ }^{6}$.

Наибольшее распространение в правоохранительной практике получило применение ИИ в системах видеонаблюдения и прогностической аналитике. Наибольший положительный опыт в этом н аправлении имеет Москва, где внедрена разветвленная система видеонаблюдения с функцией распознавания лиц, к которой подключены 167 тыс. видеокамер, обслуживающих 95\% подъездов жилых домов. С помощью этой технологии раскрывается около 70\% всех зарегистрированных преступлений ${ }^{7}$.

Считаю и необходимым обратиться к зарубежному опыту в сфере применения ИИ в правоохранительной сфере.

В Европейской хартии использования ИИ, США отмечены как ведущее государство в использовании ИИ в правоохранительной сфере [4, с. 324-334].

Например, ИИ используется для распознавания людей, изменивших свою

${ }^{6}$ URL: https://digital.report/facebook-namerenprotivostoyat-ekstremizmu-s-pomoshhyuiskusstvennogo-intellekta, дата обращения 20.11.2021г

7 Москва. Умный город. Система видеонаблюдения в Москве, 2020. URL: https://www.mos.ru/ news/item. внешность с помощью пластические операции, по фотографиям и видео. При этом выдаются варианты их первоначальной внешности. Программа «Nigel» определяет криминальные ситуации, связанные, например, с похищением детей. Программа Mayhem распознает индивидуальный почерк хакеров, определяет их местонахождение, прогнозирует хакерские атаки. Программа «CEG» устанавливает вероятность роста преступности [15, c. 111-113].

Высоких показателей в разработке ИИ достиг Китай. Так, при отслеживании каждого жителя страны ИИ составляется рейтинг, который повышается и понижается в зависимости от поступков гражданина, на основе анализа 160 тыс. параметров [28, с. 762]. Такой приём позволяет пополнять базу данных потенциальных преступников и раскрывать преступления при первом совершении преступления. ИИ с помощью видеосистемы распознавания лиц информирует правоохранительные органы о подозрительных субъектах ${ }^{8}$.

Проводимые криминологический, криминалистические исследования пополняют научный потенциал об использовании ИИ, выявлении направлений по повышению оперативности и эффективности раскрытия и расследования преступлений экстремистской направленности, совершенных с использованием информационно-телекоммуникационных сетей.

Изложенное выше, результаты исследований позволяют назвать следующие перспективные направления применения ИИ при противодействии преступным действиям эктремисткой направленности.

- через распознавание экстремистских материалов определение местонахождение устройств, их передавших;

- через содержание текста экстремисткой направленности, размещённого в сети Интернет, установление психофизиологического портрета лица его (текста) автора;

- отграничение экстремистских материалов от неэкстремистских;

- посредством комплексной (одновременной) обработки информации поиск киберэкстремистов (Интернет, мобильной связи, камер систем видеонаблюдения, спутниковой навигации), в том числе изменившего внешность с помощью пластической операции и места их нахождения.

8 Как искусственный интеллект влияет на судьбы
людей. URL: https://www.kaspersky.ru/blog/whenлюдей. UR
ai-decides.
101
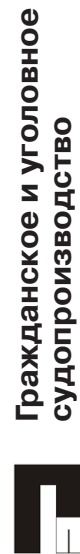


\section{Литература}

1. Регулирование робототехники: введение в «робоправо». Правовые аспекты развития робототехники и технологий искусственного интеллекта / В.В. Архипов, В.В. Бакуменко, А.Д. Волынец и др.; под ред. А.В. Незнамова. - М.: Инфотропик Медиа, 2018.

2. Философский энциклопедический словарь. - М.: Советская энциклопедия, 1983.

3. Антонов, А.А. Искусственный интеллект как источник повышенной опасности / А.А. Антонов // Юрист. - 2020. - № 7. - С. 69-74.

4. Бирюков, П.Н. Деятельность США в сфере использования искусственного интеллекта / П.Н. Бирюков // Международное и европейское право. - 2019. № 3. - C. 324-334.

5. Денисов, Н.Л. Концептуальные основы формирования международного стандарта при установлении уголовной ответственности за деяния, связанные с искусственным интеллектом / Н.Л. Денисов // Международное уголовное право и международная юстиция. - 2019. - № 4. - С. 18-20.

6. Нагродская, В.Б. Новые технологии (блокчейн / искусственный интеллект) на службе права: научно-методическое пособие / В.Б. Нагродская; под ред. Л.А. Новоселовой. - М.: Проспект, 2019.

7. Афанасьев, А.Ю. Искусственный интеллект или интеллект субъектов выявления, раскрытия и расследования преступлений: что победит? / А.Ю. Афанасьев // Библиотека криминалиста. Научный журнал. - 2018. - № 3 (38). - C. 28-34.

8. Бессонов, А.А. Искусственный интеллект и математическая статистика в криминалистическом изучении преступлений: монография / А.А. Бессонов. М.: Проспект, 2021.

9. Бахтеев, Д.В. Искусственный интеллект в криминалистике: состояние и перспективы использования / Д.В. Бахтеев// Российское право. Образование, практика, наука. - 2018. - № 2. - С. 43-49.

10. Грачева, Ю.В. Роботизация и искусственный интеллект: уголовно-правовые риски в сфере общественной безопасности / Ю.В. Грачева, А.А. Арямов// Актуальные проблемы российского права. - 2020. - № 6. - С. 169-178.

11. Закиров, Р.Ф. Использование современных IT-технологий как средство достижения основных задач судопроизводства / Р.Ф. Закиров // Вестник гражданского процесса. - 2018. - № 1. - С. 211-219.

12. Волынский, А.Ф. Компьютерная криминалистика в системе уголовноправовой защиты «традиционной» и цифровой экономики: монография / А.Ф. Волынский, В.А. Прорвич. - М.: Экономика, 2020.

13. Понкин, И.В. Искусственный интеллект с точки зрения права / И.В. Понкин, А.И. Редькина // Вестник РУДН. Сер.: Юридические науки. - 2018. - Т. 22. - № 1. - С. 91-109.

14. Морхат, П.М. Возможности, особенности и условия применения искусственного интеллекта в юридической практике / П.М. Морхат// Администратор суда. - 2018. - № 2. - С. 8-12.

15. Овчинский, В.С. Искусственный интеллект. Большие данные. Преступность («Коллекция Изборского клуба») / В.С. Овчинский, Е.С. Ларина. - М: Книжный мир, 2018

16. Синельникова, В.Н. Права на результаты искусственного интеллекта / В.Н. Синельникова, О.В. Ревинский// Копирайт. Вестник Российской академии интеллектуальной собственности. - 2017. - № 4. - С. 17-27.

17. Волынский, А.Ф. Электронное судопроизводство по преступлениям в сфере экономики (научно-практические аспекты): монография/ А.Ф. Волынский, В.А. Прорви. - М.: Экономика, 2019.

18. Афанасьев, С.Ф. К вопросу о законодательном регулировании искусственного интеллекта / С.Ф. Афанасьев // Российская юстиция. - 2020. - № 7. - С. 46-49.

19. Кибальник, А.Г. Искусственный интеллект: вопросы уголовно-правовой доктрины, ожидающие ответов / А.Г. Кибальник, П.В. Волосюк// Вестник Нижегородской академии МВД России. - 2018. - № 4(44). - С. 173-178.

20. Бычков, В.В. Искусственный интеллект в борьбе с экстремизмом / В.В. Бычков, В.А. Прорвич// Российский журнал правовых исследований. - 2020. - Том 7. - № 4. - C. 9-18.

21. Бычков, В.В. Искусственный интеллект как средство противодействия преступлениям экстремистской направленности, совершаемым с использованием информационно-телекоммуникационных сетей, в том числе сети «Интернет»/ В.В. Бычков, В.А. Прорвич // Вестник Московской академии Следственного комитета Российской Федерации. - 2020. - № 4. - С. 47-52.

22. Бычков, В.В. Искусственный интеллект: государственная политика и векторы применения / В.В. Бычков // Расследование преступлений: проблемы и пути их решения. - 2020. - № 4. - С. 45-50.

23. Бегишев, И.Р. Криминологические риски применения искусственного интеллекта / И.Р. Бегишев, З.И. Хисамова// Всероссийский криминологический журнал. - 2018. - Т. 12. - № 6. - С. 767-775. 
24. Мосечкин, И.Н. Искусственный интеллект и уголовная ответственность: проблемы становления нового вида субъекта преступления / И.Н. Мосечкин// Вестник Санкт- Петербургского университета. Право. - 2019. - Т. 10. - Вып. 3. - C. 461-476.

25. Багмет, А.М. Расследование массовых беспорядков, в том числе с участием несовершеннолетних, и вовлечения в них несовершеннолетних: учебное пособие / А.М. Багмет, В.В. Бычков. - М: ЮНИТИ-ДАНА, 2021.

26. Барчуков, В.К. Использование искусственного интеллекта в деятельности правоохранительных органов зарубежных стран / В.К. Барчуков // Международное публичное и частное право. - 2020. - № 5. - С. 19-21.

27. Попова, Н.Ф. Применение технологий искусственного интеллекта в правоохранительной деятельности / Н.Ф. Попова // Административное право и процесс. - 2021. - № 3. - С. 29-32.

28. Суходолов, А.П. Искусственный интеллект в противодействии преступности, ее прогнозировании, предупреждении и эволюции / А.П. Суходолов, А.М. Бычкова // Всероссийский криминологический журнал. - 2018. - Т. 12. - № 6. - C. 753-766.

\section{References}

1. Regulirovaniye robototekhniki: vvedeniye v «robopravo». Pravovyye aspekty razvitiya robototekhniki i tekhnologiy iskusstvennogo intellekta / V.V. Arkhipov, V.V. Bakumenko, A.D. Volynets i dr.; pod red. A.V. Neznamova. - M.: Infotropik Media, 2018.

2. Filosofskiy entsiklopedicheskiy slovar' - M.: Sovetskaya entsiklopediya, 1983.

3. Antonov, A.A. Iskusstvennyy intellekt kak istochnik povyshennoy opasnosti / A.A. Antonov // Yurist. - 2020. - № 7. - S. 69-74.

4. Biryukov, P.N. Deyatel'nost' SSHA v sfere ispol'zovaniya iskusstvennogo intellekta / P.N. Biryukov // Mezhdunarodnoye i yevropeyskoye pravo. - 2019. - № 3. - S. 324-334.

5. Denisov, N.L. Kontseptual'nyye osnovy formirovaniya mezhdunarodnogo standarta pri ustanovlenii ugolovnoy otvetstvennosti za deyaniya, svyazannyye s iskusstvennym intellektom / N.L. Denisov // Mezhdunarodnoye ugolovnoye pravo i mezhdunarodnaya yustitsiya. - 2019. - № 4. - S. 18-20.

6. Nagrodskaya, V.B. Novyye tekhnologii (blokcheyn / iskusstvennyy intellekt) na sluzhbe prava: nauchno-metodicheskoye posobiye / V.B. Nagrodskaya; pod red. L.A. Novoselovoy. - M.: Prospekt, 2019.

7. Afanas'yev, A.YU. Iskusstvennyy intellekt ili intellekt sub"yektov vyyavleniya, raskrytiya i rassledovaniya prestupleniy: chto pobedit? / A.YU. Afanas'yev // Biblioteka kriminalista. Nauchnyy zhurnal. - 2018. - № 3 (38). - S. 28-34.

8. Bessonov, A.A. Iskusstvennyy intellekt i matematicheskaya statistika v kriminalisticheskom izuchenii prestupleniy: monografiya / A.A. Bessonov. - M.: Prospekt, 2021.

9. Bakhteyev, D.V. Iskusstvennyy intellekt v kriminalistike: sostoyaniye i perspektivy ispol'zovaniya / D.V. Bakhteyev// Rossiyskoye pravo. Obrazovaniye, praktika, nauka. - 2018. - № 2. - S. 43-49.

10. Gracheva, YU.V. Robotizatsiya i iskusstvennyy intellekt: ugolovno-pravovyye riski v sfere obshchestvennoy bezopasnosti /YU.V. Gracheva, A.A. Aryamov// Aktual'nyye problemy rossiyskogo prava. - 2020. - № 6. - S. 169-178.

11. Zakirov, R.F. Ispol'zovaniye sovremennykh IT-tekhnologiy kak sredstvo dostizheniya osnovnykh zadach sudoproizvodstva / R.F. Zakirov // Vestnik grazhdanskogo protsessa. - 2018. - № 1. - S. 211-219.

12. Volynskiy, A.F. Komp'yuternaya kriminalistika v sisteme ugolovno-pravovoy zashchity «traditsionnoy» i tsifrovoy ekonomiki: monografiya / A.F. Volynskiy, V.A. Prorvich. - M.: Ekonomika, 2020.

13. Ponkin, I.V. Iskusstvennyy intellekt s tochki zreniya prava / I.V. Ponkin, A.I. Red'kina // Vestnik RUDN. Ser.: Yuridicheskiye nauki. - 2018. - T. 22. - № 1. - S. 91-109.

14. Morkhat, P.M. Vozmozhnosti, osobennosti i usloviya primeneniya iskusstvennogo intellekta v yuridicheskoy praktike / P.M. Morkhat// Administrator suda. - 2018. - № 2. - S. 8-12.

15. Ovchinskiy, B.C. Iskusstvennyy intellekt. Bol'shiye dannyye. Prestupnost' («Kollektsiya Izborskogo kluba») / B.C. Ovchinskiy, Ye.S. Larina. - M: Knizhnyy mir, 2018.

16. Sinel'nikova, V.N. Prava na rezul'taty iskusstvennogo intellekta / V.N. Sinel'nikova, O.V. Revinskiy// Kopirayt. Vestnik Rossiyskoy akademii intellektual'noy sobstvennosti. - 2017. - № 4. - S. 17-27.

17. Volynskiy, A.F. Elektronnoye sudoproizvodstvo po prestupleniyam v sfere ekonomiki (nauchno-prakticheskiye aspekty): monografiya/ A.F. Volynskiy, V.A. Prorvi. - M.: Ekonomika, 2019.

18. Afanas'yev, S.F. K voprosu o zakonodatel'nom regulirovanii iskusstvennogo intellekta / S.F. Afanas'yev // Rossiyskaya yustitsiya. - 2020. - № 7. - S. 46-49.

19. Kibal'nik, A.G. Iskusstvennyy intellekt: voprosy ugolovno-pravovoy doktriny, ozhidayushchiye otvetov / A.G. Kibal'nik, P.V. Volosyuk// Vestnik Nizhegorodskoy 
akademii MVD Rossii. - 2018. - № 4(44). - S. 173-178.

20. Bychkov, V.V. Iskusstvennyy intellekt v bor'be s ekstremizmom / V.V. Bychkov, V.A. Prorvich// Rossiyskiy zhurnal pravovykh issledovaniy. - 2020. - Tom 7. - № 4. - S. 9-18

21. Bychkov, V.V. Iskusstvennyy intellekt kak sredstvo protivodeystviya prestupleniyam ekstremistskoy napravlennosti, sovershayemym s ispol'zovaniyem informatsionnotelekommunikatsionnykh setey, v tom chisle seti «Internet»/ V.V. Bychkov, V.A. Prorvich // Vestnik Moskovskoy akademii Sledstvennogo komiteta Rossiyskoy Federatsii. - 2020. - № 4. - S. 47-52.

22. Bychkov, V.V. Iskusstvennyy intellekt: gosudarstvennaya politika i vektory primeneniya / V.V. Bychkov // Rassledovaniye prestupleniy: problemy i puti ikh resheniya. - 2020. - № 4. - S. 45-50.

23. Begishev, I.R. Kriminologicheskiye riski primeneniya iskusstvennogo intellekta / I.R. Begishev, Z.I. Khisamova// Vserossiyskiy kriminologicheskiy zhurnal. - 2018. - T. 12. - № 6. - C. 767-775.

24. Mosechkin, I.N. Iskusstvennyy intellekt i ugolovnaya otvetstvennost': problemy stanovleniya novogo vida sub"yekta prestupleniya / I.N. Mosechkin// Vestnik SanktPeterburgskogo universiteta. Pravo. - 2019. - T. 10. - Vyp. 3. - S. 461-476.

25. Bagmet, A.M. Rassledovaniye massovykh besporyadkov, v tom chisle $\mathrm{s}$ uchastiyem nesovershennoletnikh, i vovlecheniya $v$ nikh nesovershennoletnikh: uchebnoye posobiye / A.M. Bagmet, V.V. Bychkov. - M: YUNITI-DANA, 2021.

26. Barchukov, V.K. Ispol'zovaniye iskusstvennogo intellekta $v$ deyatel'nosti pravookhranitel'nykh organov zarubezhnykh stran / V.K. Barchukov // Mezhdunarodnoye publichnoye i chastnoye pravo. - 2020. - № 5. - S. 19-21.

27. Popova, N.F. Primeneniye tekhnologiy iskusstvennogo intellekta $v$ pravookhranitel'noy deyatel'nosti / N.F. Popova // Administrativnoye pravo i protsess. - 2021. - № 3. - S. 29-32.

28. Sukhodolov, A.P. Iskusstvennyy intellekt v protivodeystvii prestupnosti, yeye prognozirovanii, preduprezhdenii i evolyutsii / A.P. Sukhodolov, A.M. Bychkova // Vserossiyskiy kriminologicheskiy zhurnal. - 2018. - T. 12. - № 6. - S. 753-766.

Бычков Василий Васильевич, кандидат юридических наук, доцент, декан факультета повышения квалификации Московской академии Следственного комитета Российской Федерации. 125080, г. Москва, ул. Врубеля, д. 12. E-mail: bychkov_vasilij@bk.ru

BYCHKOV Vasily Vasilevich, PhD (law), associate professor, dean of the faculty of excellence of the Moscow academy of the Investigative committee of the Russian Federation. 125080, Moscow, Vrubelstr., 12. E-mail: bychkov_ vasilij@bk.ru 